\title{
Research Advances in Ion Channel-based Electrochemical Sensing Techniques
}

\author{
JIANG Xiao-Jing ${ }^{1,2}$, LIANG Rong-Ning ${ }^{1, *}$, QIN Wei ${ }^{1, *}$ \\ ${ }^{1}$ Key Laboratory of Coastal Environmental Processes and Ecological Remediation, Yantai Institute of Coastal Zone Research, Chinese \\ Academy of Sciences, Shandong Provincial Key Laboratory of Coastal Environmental Processes, YICCAS, Yantai 264003, China \\ ${ }^{2}$ University of Chinese Academy of Sciences, Beijing 100049, China
}

\begin{abstract}
During the past few years, the electrochemical sensing techniques based on ion channels have attracted considerable attention. Nowadays, these techniques have been widely used in DNA sequencing, measurement of molecular interactions, and detection of inorganic ions and biological species. Hence, in this review, the research progresses of the ion channel-based electrochemical techniques including amperometry, conductometry and potentiometry in chemical and biological sensing are addressed from the perspective of different electrochemical methods. The sensing mechanism and fabrication process of these sensing methods are mainly introduced. In addition, the further research orientations of the electrochemical sensing based on ion channels are prospected.
\end{abstract}

Key Words: Ion channel; Electrochemical technique; Chemical and biological sensing; Review

\section{Introduction}

In nature, the metabolism of organisms requires constant material exchange and energy transfer with the external environment. This process is modulated by ion channels. Natural ion channels are hydrophilic protein microchannels in the cell membrane that allow certain ions to enter and leave the cell. Selectivity and gating are physiological features that regulate when and what ions pass through ion channels. Selectivity facilitates the diffusion of ions down the electrochemical gradient across cell membranes, and gating refers to the opening and closing of the channel, making it sensitive to external stimuli. Ion channels can be classified into two categories: biological and synthetic channels. Biological ion channels are mainly composed of biofilm, transmembrane protein, and channels, which are assorted into $\alpha$-hemolysin ( $\alpha$-HL), aerolysin, Mycobacteria smegmatis porin A (MspA), and outer membrane protein $\mathrm{G}(\mathrm{OmpG})$ of Escherichia coli. Synthetic ion channels with diameters comparable to biological protein pores have been successfully fabricated on the substrate materials ${ }^{[1-8]}$ including polymer, silicon, glass, $\mathrm{Al}_{2} \mathrm{O}_{3}$, graphene, and $\mathrm{MoS}_{2}$, by using ion beam ${ }^{[9]}$ or electron beam sculpting ${ }^{[10]}$. For ion channel sensing, biological ion channels are particularly appealing due to their strong signal resolution, atomic-precision, and structural reproducibility. However, such channels usually suffer from poor stability and are not suitable for large-scale production. Synthetic ion channels have tunable properties, such as controllable pore sizes, easy to prepare arrays, as well as enhanced mechanical, thermal, and chemical stability. Nevertheless, the large cost to synthesize ${ }^{[11]}$ and noise ${ }^{[12]}$ are regarded as the major challenges, which limit their applications.

In recent years, ion channels were widely applied in the field of chemical sensing because of their unique merits. Nowadays, various ion channel-based optical ${ }^{[13]}$ and electrochemical $^{[14]}$ sensors were developed and applied in ion detection $^{[15]}$, biosensing ${ }^{[16-19]}$, energy conversion ${ }^{[20]}$, and DNA 
sequencing ${ }^{[21,22]}$. Because electrochemistry offers great promise for ion channel-based sensing with features that include remarkable sensitivity, low cost, simple operation and inherent miniaturization, the electrochemical sensing techniques based on ion channels attracted considerable attention. The concept of electrochemical sensing using ion channels was based on the Coulter counter, which was developed for the use of counting erythrocyte translocation through a micrometer-sized hole. Umezawa et $a l^{[23,24]}$ firstly introduced ion channels into the field of electrochemical sensing and successfully detected various inorganic ions such as $\mathrm{ClO}_{4}^{-}, \mathrm{Ca}^{2+}, \mathrm{Mg}^{2+}$ and $\mathrm{Ba}^{2+}$. With the recent development of ion channel-based electrochemical technology, the detection of biological macromolecules (such as single-stranded $\mathrm{DNA}^{[25]}$, double-stranded DNA ${ }^{[26]}, \mathrm{RNA}^{[27]}$ and proteins ${ }^{[28-30]}$ ), DNA sequencing and interactions between DNA and protein were achieved. Various applications of ion-channel electrochemical sensing are shown in Fig.1. Herein, we provided an up-to-date overview of the field of ion channelbased electrochemical sensing. We covered the traditional sensing platforms, including biological ion channels and synthetic ion channels, with a focus on the recent demonstrations of new applications in chemical and biological sensing based on different electrochemical signal transductions.

\section{Ion channel-based electrochemical sensing techniques}

For ion channel-based electrochemical sensing techniques, the ion channel is used as the recognition element for the analyte. When the targets flow through the ion channel, a signal is obtained by the transducer and subsequently converted to an electrochemical signal. After signal magnification and storage, the signal is recorded by an electrochemical instrument. Depending on the format of electrochemical output signal, the electrochemical ion-channel technique can be classified as amperometry, conductometry, or potentiometry.

\subsection{Amperometric ion-channel sensing technique}

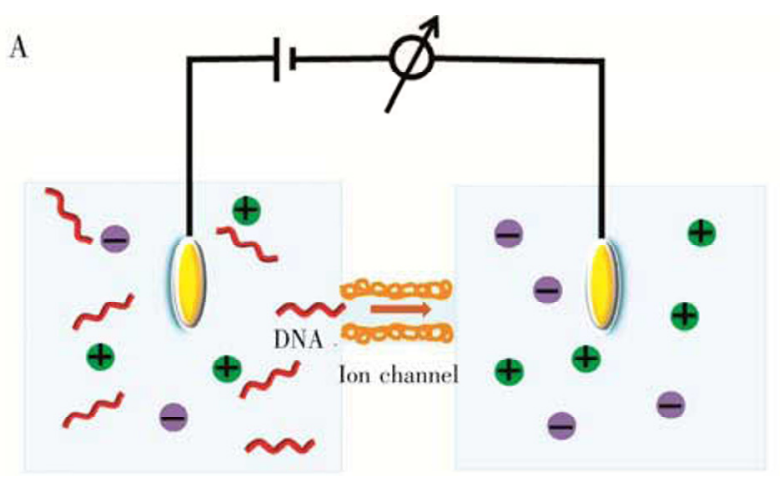

B

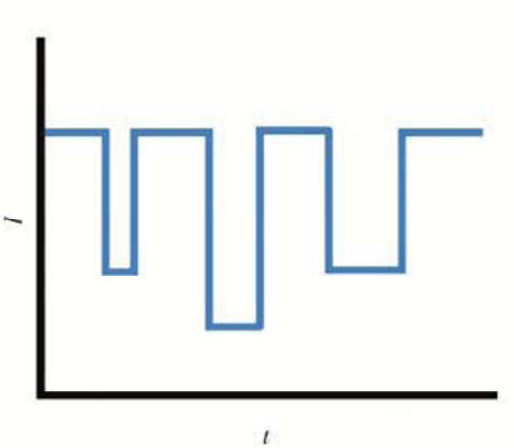

Fig.2 (A) Schematic diagram and (B) typical response curve for current-based ion channel sensing of DNA ${ }^{[14]}$ 
the length of the molecule. This seminal work sparked the field of ion-channel sensing and set the foundation for further advancements to be made. Long and co-workers developed a method for direct electrochemical detection of unmodified oligonucleotides with an Aerolysin ion channel ${ }^{[39]}$. Note that, although these methods were groundbreaking, they exhibited insufficient selectivity towards the target. Both the target and non-target molecules with similar volume could enter ion channel, thus reducing the detection accuracy.

To solve this problem, the auxiliary species with the certain functional groups were modified onto the surface of ion channels or the targets. For biological ion channels, Fahie et $a l^{[40]}$ detected biotin-binding proteins using a biotin ligand tethered to the rim of an OmpG ion channel. The proposed channel could resolve subtle differences in the surface property between highly homologous protein analytes ${ }^{[41]}$. For synthetic ion channels, the specificity is usually improved by covalent functionalization. In the work of Jiang and co-workers, G-quadruplex DNA was immobilized onto synthetic ion channel, which underwent a potassiumresponsive conformational change and then induced a decrease in the transmembrane current. The developed nanochannel system enabled potassium ion quantification ${ }^{[42]}$. Similarly, a biomimetic, zinc-activated ion channel was prepared by incorporating a zinc finger peptide into a single polymeric nanochannel ${ }^{[43]}$, and highly selective determination of $\mathrm{Hg}^{2+}$ was achieved by modifying a certain length of ssDNA onto polymer-based synthetic ion channel ${ }^{[44]}$. Gao et al ${ }^{[45]}$ described a macrocyclic dioxotetraamine derivative functionalized glass conical ion channel that was capable of ultrasensitive $\mathrm{Hg}^{2+}$ detection. Wang et al ${ }^{[46]}$ reported an electrostatic-gated transport in chemically modified glass ion channel. In this work, amine functionlization of the interior pore surface introduced $\mathrm{pH}$-dependent ion selectivity at the pore orifice, a consequence of the electrostatic interactions between the redox ions and protonated surface amines. In addition, the selectivity of ion channel for a given target can also be improved by modifying functionalized species on the target analytes. For instance, a small polycationic nanocarrier was engineered onto the target nucleic acid to impose a prescribed dipole moment, thus granting both sensitivity and selectivity to the ion channel detection method ${ }^{[47]}$. Subject to the electric field gradient at the channel entrance, all target molecules bound to a nanocarrier were driven into the channel by the dielectrophoresis force, while the nontarget molecules without the bound carriers, were electrophoretically repelled from ion channel and thus did not generate any interfering signals.

A prevailing problem in the traditional current-based ion-channel sensing techniques is that the transport kinetics of the analytes is often faster than the measurement time resolution. One way to resolve this problem is to slow down the molecule transport and prolong their residence time within the ion channel to obtain time-resolvable signals. Meller et al contributed to slow down the translocation speed of proteins. They discovered that, by imposing a laser-induced electroosmotic flow in the opposite direction of the analyte's electrophoretic motion, the translocation speed could be effectively slowed, which enabled detection of a small protein $^{[48]}$. Additionally, further work showed that by finetuning the electrolyte $\mathrm{pH}$ to the isoelectric point (pI) of the analyte protein, the translocation speed of the analyte protein could also decrease ${ }^{[49]}$. Researches on monitoring and decreasing the translocation speed of DNA through ion channels were done by Dekker and co-workers ${ }^{[50]}$. By monitoring the relative position of the markers when the DNA moves through the channel, the translocation velocity could be determined. In addition, they reported an approach that used the glutamate solutions to slow down DNA translocation. In comparison to the conventionally used KCl-based solutions, the glutamate-based solutions had lower conductivity and greater viscosity. An electrolyte solution with increased viscosity increased the dragging force on the DNA molecules, resulting in longer translocation times. However, it should be noted that this technique usually suffered from the problem of the decreased conductivity of glutamate salt solutions which could result in a reduction in current blockade amplitude. In view of this, Plesa et $a l^{[51]}$ used the high-concentrated $\mathrm{LiCl}$ buffers to reduce the speed of DNA molecules. In this case, a higher measurement bandwidth could be obtained.

\subsection{Conductometric ion-channel sensing technique}

Conductometry-based ion channel sensing system is mainly comprised of ion channel and electrolyte solution. The output impedance is measured and recorded by an impedance analyzer at room temperature. The mechanism of traditional conductometry is based on charge transfer at the electrode/ electrolyte interface. Electron transfer resistance is generated as a result of the difference between the electron conduction rate and the solution ion conduction rate. For traditional conductometry, the diameter of the semicircle in the impedance spectrum is equal to the charge transfer resistance, which is often used as the characteristic resistance. The functionalization of ion channels can decrease the electron transfer resistance slightly, but the interactions between functionalized ion channels and analytes can significantly increase the electron transfer resistance. This increased electron transfer resistance then makes it possible to detect various parameters, such as analyte concentration, charging condition, and structural characteristics. The detection diagram and typical impedance spectroscopy for impedance- based ion-channel sensing are illustrated in Fig.3. Although this technique has the advantages of a simple signal transduction and high sensitivity ${ }^{[52-55]}$, it suffered from the drawbacks of the difficulty in analyzing complex electrochemical 

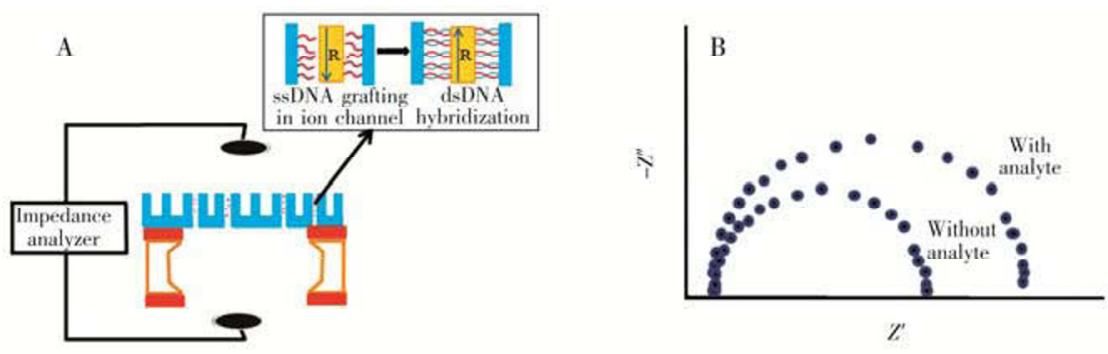

Fig.3 (A) Detection diagram and (B) typical impedance spectroscopy for impedance-based ion-channel sensing of DNA hybridization ${ }^{[56]}$

impedance spectra and the lack of uniqueness in equivalent circuit model. At present, such technique is mainly used for the detection of biomacromolecules ${ }^{[56]}$.

Synthetic alumina-based ion channel is a very attractive platform for development of the ion-channel biosensing devices owing to its uniform pore size, high surface area and low unspecific adsorption. Because the unmodified aluminabased ion channels cannot be employed to achieve highly selective impedance detection, modified alumina channels are most frequently used in the previously reported literatures. $\mathrm{Wu}$ et $a l^{[56]}$ functionalized the alumina ion channel by using ssDNA for conductometric detection of DNA hybridization. With low channel density, ion-channel resistance and membrane capacitance could be clearly identified in the electrochemical impedance spectrum. Kant et al ${ }^{[57]}$ developed a method for the covalent attachment of streptavidin to the internal surface of nanoporous alumina ion channels for conductometric label- free biosensing. The influence of the area and pore number of alumina channel on detection sensitivity was investigated. The experimental result showed that better sensing performance could be obtained by using channels with smaller area and lower pore number. Recently, an electrochemical biosensor based on human odorant binding proteins (hOBPs) modified alumina channel was developed to detect specific biomolecular ligands, such as aldehydes and fatty acids ${ }^{[5]}$. hOBPs could not only interact with lipophilic molecules but also show high affinities towards the hydrophilic molecules including aldehydes and fatty acids. The interactions between hOBPs and the hydrophilic molecules would lead to an obvious increase in the series impedance of channel and charge transfer. The detection limits of the proposed approach for benzaldehyde and docosahexaenoic acid were about $10^{-9} \mathrm{mg} \mathrm{mL}^{-1}$ and $10^{-12}$ $\mathrm{mg} \mathrm{mL} \mathrm{m}^{-1}$, respectively.

\subsection{Potentiometric ion-channel sensing technique}

Potentiometric ion-channel sensors mainly refer to the ionselective electrode (ISE)-based ion-channel sensors. Polymeric membrane ISEs have been routinely used for determination of ionic species in clinical and water quality applications owing to their attractive features including excellent selectivity, low cost, ease of use and high reliability.
By combining ISEs with ion channels, inorganic ions and biomacromolecules can be sensitively and selectively determined. It is expected that the application of these sensors will provide a promising measurement technique for clinical testing and environmental monitoring. Compared to other electrochemical sensors based on ion channels, potentiometric ion-channel sensor is much simpler and more selective. However, the regeneration of such sensor is a bit difficult since there is no additional electrochemical driving force in the recognition process.

Current potentiometric ion-channel sensing techniques can be classified into two categories: zero-current and currentdriven techniques. Under the zero-current conditions, a twoelectrode system which was composed of the ion-channelbased ISE and external reference electrode was utilized. Both electrodes were connected with conducting wire and placed in the sample solution to form a galvanic cell. In this system, the analyte in the sample solution could interact with the recognition molecules in the inner surface of ion channels, partially blocking the indicator ion transfer across the membrane/aqueous sample interface, and subsequently caused the potential change that was recorded by the potentiometer. Such a potential change could be utilized to measure the concentration of the analyte in the sample. Note that, in twoelectrode system, the diffusion of the indicator ion was driven only by the concentration difference. For current-driven potentiometry, pulsed galvanostatic chronopotentiometry, which could rapidly and accurately control the ion extraction process, was applied to directly monitor the blocking effect induced by the recognition reactions in ion channels ${ }^{[58]}$. Generally, a three-electrode system consisting of a working electrode, reference electrode and auxiliary electrode was employed.

Gyurcsanyi et $a l^{[59]}$ combined functionalized ion channels with ISEs to detect miRNA (Fig.4). A charge inversion occurred in the sensing zone of a nanochannel when negatively charged microRNA strands bound to positively charged peptidenucleic acid (PNA) modified channels, promoting the transfer of the indicator ion, $\mathrm{K}^{+}$. The resultant concentration change of $\mathrm{K}^{+}$was detected by the $\mathrm{K}^{+}$-selective electrode and thus the miRNA could be subsequently determined. However, in this sensing system, the recognition process and the determination process were performed separately. Moreover, the selectivity 

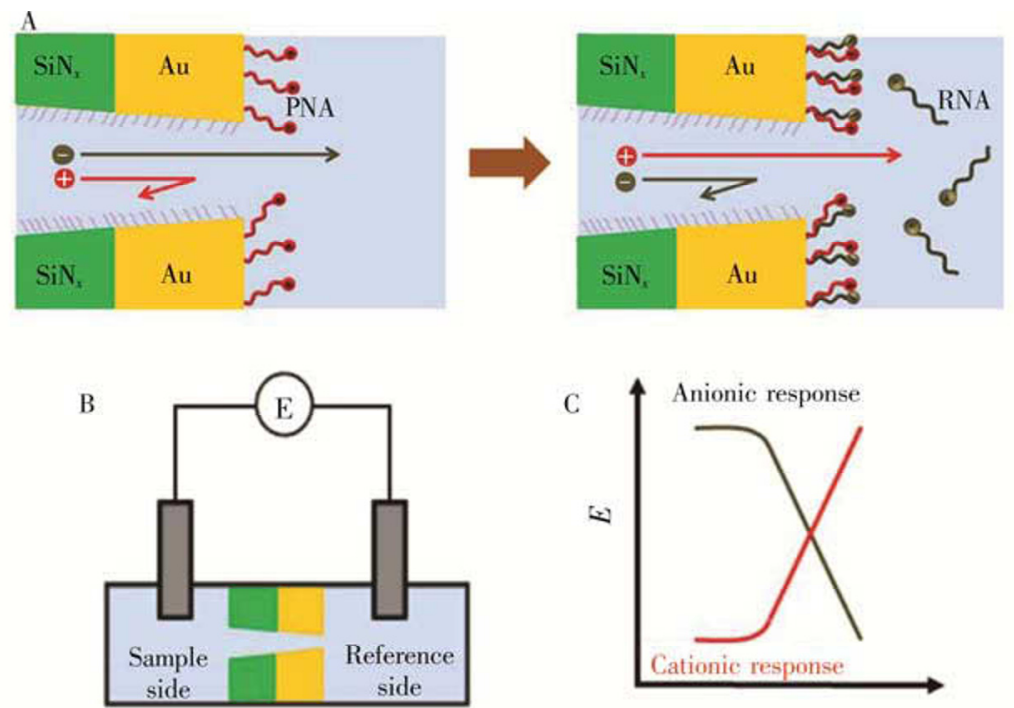

$\lg C$

Fig.4 (A) Schematic illustration, (B) measurement setup and (C) typical potential response for equilibrium potential-based ion-channel sensing of microRNA ${ }^{[59]}$

of the proposed sensor only depended on the charge change of ion-channel surface. To solve this problem, further efforts were made by incorporating hydrophobic ionophore into the wall of gold nanochannels for $\mathrm{Ag}^{+}$detection (Fig.5). The new ISE construction preserved the exquisite selectivity of ionophores in a robust solid-state membrane format with all active components covalently immobilized ${ }^{[60]}$. Very recently, the same group ${ }^{[61]}$ reported the synthesis and analytical application of the first $\mathrm{Cu}^{2+}$-selective synthetic ion channel on the basis of hydrophilic peptide-modified gold nanochannels.

Bakker et $a l^{[62]}$ proposed an ion-channel sensing technique based on chronopotentiometry for sensitive detection of protein (Fig.6). An avidin-biotin interaction was used as a model system. In that system, avidin accumulated on the ion-selective membrane surface modified by biotin, partially blocking the current-induced $\mathrm{Na}^{+}$ion transfer across the membrane/aqueous sample interface, and subsequently decreased the potential jump. Such a potential drop could be utilized to measure the concentration of avidin in the sample solution. Because the sensitivity of protein sensing was dependent on the effective blocking of the active surface area, the detection sensitivity could be improved with ion channel applied on top of the biotinylated ion-selective membrane surface.

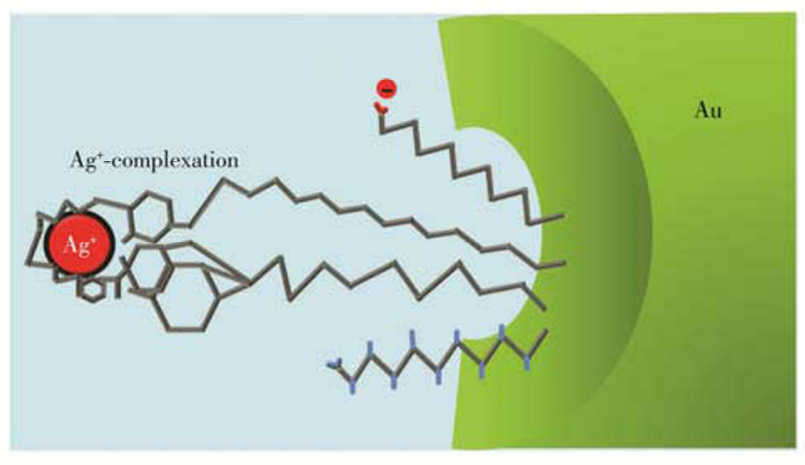

Fig.5 Schematic of the gold-based ion channel modified with ionophore $^{[60]}$

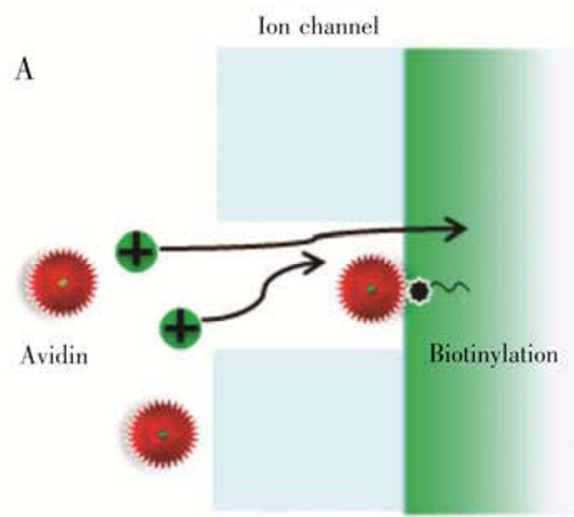

B

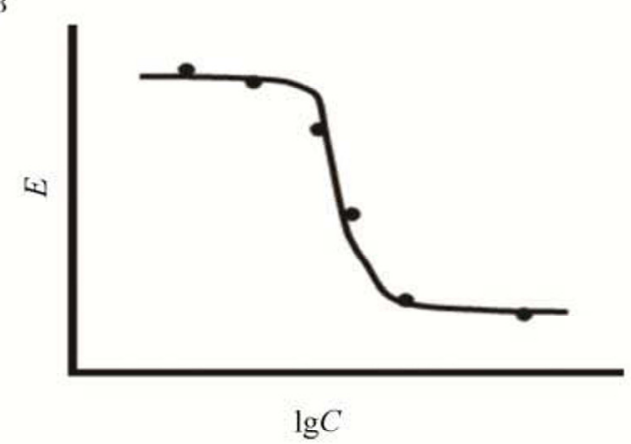

Fig.6 (A) Detection diagram and (B) typical potential response for potentiometry-based ion-channel sensing of antigen-antibody interactions ${ }^{[62]}$ 


\section{Conclusions}

In the past 10 years, spectacular progress was made in the field of ion channel-based electrochemical sensing techniques. This review summarized the recent research progresses of ion channel-based electrochemical techniques in chemical and biological sensing from the perspective of different electrochemical methods. Although significant breakthroughs have been gained in selectivity, sensing capability and stability, these techniques still face challenges in diversity, stability, and homogeneity of ion channels. Certainly, this situation may be dramatically changed with the development of nanotechnology, DNA engineering techniques, and 3D printing technique. In addition, it is very important to note that very few ion-channel electrochemical sensors are finally applied in the real sample analysis. Most of these sensors are still mainly at the experimental stage. Hence, much effort should be devoted to the applications of these sensors in rapid and on-site analysis.

\section{References}

[1] Apel P. Radiat. Meas., 2001, 34(1-6): 559-566

[2] Keyser U F, Krapf D, Koeleman B N, Smeets R M M, Dekker N H, Dekker C. Nano Lett., 2005, 5(11): 2253-2256

[3] Krapf D, Wu M Y, Smeets R M M, Zandbergen H W, Dekker C, Lemay S G. Nano Lett., 2006, 6(1): 105-109

[4] Salancon E, Tinland B. J. Colloid Interf. Sci., 2013, 392: 465-469

[5] Lu Y L, Zhang D M, Zhang Q, Huang Y X, Luo S B, Yao Y, Li S, Liu Q J. Biosens. Bioelectron., 2016, 79: 251-257

[6] Avdoshenko S M, Nozaki D, da Rocha C G, Gonzalez J W, Lee M H, Gutierrez R, Cuniberti G. Nano Lett., 2013, 13(5): 1969-1976

[7] Merchant C A, Healy K, Wanunu M, Ray V, Peterman N, Bartel J, Fischbein M D, Venta K, Luo Z T, Johnson A T C, Drndic M. Nano Lett., 2010, 10(8): 2915-2921

[8] Feng J, Liu K, Graf M, Lihter M, Bulushev R D, Dumcenco D, Alexander D T L, Krasnozhon D, Vuletic T, Kis A, Radenovic A. Nano Lett., 2015, 15(5): 3431-3438

[9] Li J, Stein D, McMullan C, Branton D, Aziz M J, Golovchenko J A. Nature, 2001, 412(6843): 166-169

[10] Storm A J, Chen J H, Ling X S, Zandbergen H W, Dekker C. Nat. Mater, 2003, 2(8): 537-540

[11] Zhan S X, Zhang X H, Wang N, Yang X R, Guo M. Mater. Rev., 2012, (19): 13-16

[12] Yan B Y, Gu Z, Gao R, Cao C, Ying Y L, Ma W, Long Y T. Chinese J. Anal. Chem., 2015, 43(7): 971-975

[13] Gilboa T, Meller A. Analyst, 2015, 140(14): 4733-4747

[14] Makra I, Gyurcsanyi R E. Electrochem. Commun., 2014, 43: 55-59

[15] Braha O, Gu L Q, Zhou L, Lu X, Cheley S, Bayley H. Nat.
Biotechnol., 2000, 18(9): 1005-1007

[16] Zahid O K, Wang F, Ruzicka J A, Taylor E W, Hall A R. Nano Lett., 2016, 16(3): 2033-2039

[17] Ayub M, Stoddart D, Bayley H. ACS Nano, 2015, 9(8): 7895-7903

[18] Harrington L, Alexander L T, Knapp S, Bayley H. Angew. Chem. Int. Ed., 2015, 54(28): 8154-8159

[19] Nivala J, Mulroney L, Li G, Schreiber J, Akeson M. ACS Nano, 2014, 8(12): 12365-12375

[20] Gomez V, Ramirez P, Cervera J, Nasir S, Ali M, Ensinger W, Mafe S. Appl. Phys. Lett., 2015, 106(7): 073701

[21] Kowalczyk S W, Tuijtel M W, Donkers S P, Dekker C. Nano Lett., 2010, 10(7): 1414-1420

[22] Venkatesan B M, Bashir R. Nat. Nanotechnol., 2011, 6(10): 615-624

[23] Sugawara M, Kojima K, Sazawa H, Umezawa Y. Anal. Chem., 1987, 59(24): 2842-2846

[24] Minami H, Sugawara M, Odashima K, Umezawa Y, Uto M. Michaelis E K, Kuwana T. Anal. Chem., 1991, 63(23): 2787-2795

[25] Plesa C, van Loo N, Ketterer P, Dietz H, Dekker C. Nano Lett., 2015, 15(1): 732-737

[26] Skinner G M, van den Hout M, Broekmans O, Dekker C, Dekker N H. Nano Lett., 2009, 9(8): 2953-2960

[27] Talaga D S, Li J L. J. Am. Chem. Soc., 2009, 131(26): 9287-9297

[28] Rodriguez-Larrea D, Bayley H. Nat. Nanotechnol., 2013, 8(4): 288-295

[29] Niedzwiecki D J, Iyer R, Borer P N, Movileanu L. ACS Nano, 2013, 7(4): 3341-3350

[30] Rosen C B, Rodriguez-Larrea D, Bayley H. Nat. Biotechnol., 2014, 32(2): 179-181

[31] Cabello-Aguilar S, Abou Chaaya A, Bechelany M, Pochat-Bohatier C, Balanzat E, Janot J M, Miele P, Balme S. Soft. Matter., 2014, 10(42): 8413-8419

[32] Kaya D, Dinler A, San N, Kececi K. Electrochim. Acta., 2016, 202: 157-165

[33] Wei C, Bard A J, Feldberg S W. Anal. Chem., 1997, 69(22): $4627-4633$

[34] Zhang Y C, Chen Y L, Fu Y Q, Ying C F, Feng Y X, Huang Q M, Wang C, Pei D S, Wang D Q. Sci. Rep., 2016, 6: 27959

[35] Shim J, Humphreys G I, Venkatesan B M, Munz J M, Zou X Q, Sathe C, Schulten K, Kosari F, Nardulli A M, Vasmatzis G, Bashir R. Sci. Rep., 2013, 3: 1389

[36] Savariar E N, Krishnamoorthy K, Thayumanavan S. Nat. Nanotechnol., 2008, 3(2): 112-117

[37] Lee S B, Mitchell D T, Trofin L, Science, 2002, 296(5576): 2198-2200

[38] Kasianowicz J J, Brandin E, Branton D, Deamer D W. Proc. Natl. Acad. Sci. USA, 1996, 93(24): 13770-13773

[39] Cao C, Liao D F, Ying Y L, Long Y T. Acta Chim. Sinica, 2016, (9): 734-737 
[40] Fahie M A, Chisholm C, Chen M. ACS Nano, 2015, 9(2): 1089-1098

[41] Fahie M A, Yang B, Mullis M, Holden M A, Chen M. Anal. Chem., 2015, 87(21): 11143-11149

[42] Hou X, Guo W, Xia F, Nie F Q, Dong H, Tian Y, Wen L P, Wang L, Cao L X, Yang Y, Xue J M, Song Y L, Wang Y G, Liu D S, Jiang L. J. Am. Chem. Soc., 2009, 131(22): 7800-7805

[43] Tian Y, Hou X, Wen L P, Guo W, Song Y L, Sun H Z, Wang Y G, Jiang L, Zhu D B. Chem. Commun., 2010, 46(10): $1682-1684$

[44] Tian Y, Zhang Z, Wen L P, Ma J, Zhang Y Q, Liu W D, Zhai J, Jiang L. Chem. Commun., 2013, 49(91): 10679-10681

[45] Gao R, Ying Y L, Yan B Y, Iqbal P, Preece J A, Wu X Y. Microchim. Acta, 2016, 183(1): 491-495

[46] Wang G L, Zhang B, Wayment J R, Harris J M, White H S. J. Am. Chem. Soc., 2006, 128(23): 7679-7686

[47] Tian K, Decker K, Aksimentiev A, Gu L Q. ACS Nano, 2017, 11(2): 1204-1213

[48] Di Fiori N, Squires A, Bar D, Gilboa T, Moustakas T D, Meller A. Nat. Nanotechnol., 2013, 8(12): 946-951

[49] Nir I, Huttner D, Meller A. Biophys. J., 2015, 108(9): 2340-2349

[50] Plesa C, van Loo N, Dekker C. Nanoscale, 2015, 7(32): 13605-13609
[51] Plesa C, Verschueren D, Pud S, van der Torre J, Ruitenberg J W, Witteveen M J, Jonsson M P, Grosberg A Y, Rabin Y, Dekker C. Nat. Nanotechnol., 2016, 11(12): 1093-1097

[52] Adiga S P, Curtiss L A, Elam J W, Pellin M J, Shih C C, Shih C M, Lin S J, Su Y Y, Gittard S A, Zhang J, Narayan R J. Jom-US, 2008, 60(3): 26-32

[53] Santos A, Kumeria T, Losic D. TrAC-Trend. Anal. Chem., 2013, 44: $25-38$

[54] de la Escosura-Muniz A, Merkoci A. ACS Nano, 2012, 6(9): $7556-7583$

[55] Stroeve P, Ileri N. Trends. Biotechnol., 2011, 29(6): 259-266

[56] Wu S M, Ye W W, Yang M, Taghipoor M, Meissner R, Brugger J, Renaud P. Sens. Actuators B, 2015, 216: 105-112

[57] Kant K, Priest C, Shapter J G, Losic D. Electrochim. Acta, 2014, 139: 225-231

[58] Makarychev-Mikhailov S, Shvarev A, Bakker E. J. Am. Chem. Soc., 2004, 126(34): 10548-10549

[59] Makra I, Brajnovits A, Jagerszki G, Furjes P, Gyurcsanyi R E. Nanoscale, 2017, 9(2): 739-747

[60] Jagerszki G, Takacs A, Bitter I, Gyurcsanyi R E. Angew. Chem. Int. Ed., 2011, 123(7): 1694-1697

[61] Papp S, Jagerszki G, Gyurcsanyi R E. Angew. Chem. Int. Ed., 2018, 57(17): 4752-4755

[62] Xu Y D, Bakker E. Langmuir, 2009, 25(1): 568-573 